\title{
Pollinator attraction devices (floral fragrances) of some Brazilian orchids
}

\author{
Mariza G. Reis ${ }^{1}$, Emerson R. Pansarim², Ubiratan F. da Silva ${ }^{1,3}$, Maria do C. \\ Estanislau do Amaral' ${ }^{2}$ and Anita J. Marsaioli ${ }^{*}$ \\ ${ }^{1}$ Instituto de Química, Universidade Estadual de Campinas, CP 6154, Campinas, SP 13084-971, \\ Brasil \\ ${ }^{2}$ Departamento de Botânica, Instituto de Biologia, Universidade Estadual de Campinas, Caixa \\ Postal 6109, Campinas, SP, 13083-970, Brasil \\ ${ }^{3}$ Departamento de Química, Universidade Federal de Santa Maria, Santa Maria, RS, Brasil \\ E-mail: anita@iqm.unicamp.br \\ E-mail:volker@unicamp.br
}

\section{Dedicated to Professor Otto Gottlieb as a tribute to his contributions to natural products chemistry}

(received 16 Jan 04; accepted 30 July 04; published on the web 13 Aug 04)

\begin{abstract}
The floral fragrances of six orchids (Stanhopea lietzeii Frost ex Hooker, S. Insignis Frost ex Hooker, Polystachya estrellensis Hook. Psilochilus modestus Barb. Rodr., Epidendrum secundum $\mathrm{L}$ and E. paniculatum) from the Atlantic rain forest were investigated, attempting to link the floral fragrance composition to the rewards (pollen, nectar, pseudopollen and fragrant oil). From this evaluation we conclude that in most pollinations, the attraction could not be assigned to one compound or class of compounds but to the "bouquet" that is an ensemble of compounds belonging to different compound classes.
\end{abstract}

Keywords: Stanhopea lietzeii Frost ex Hooker, S. Insignis Frost ex Hooker, Polystachya estrellensis Hook. Psilochilus modestus Barb. Rodr., Epidendrum secundum.and E. paniculatum, floral fragrance, pollinators

\section{Introduction}

Volatile substances have long been recognized as the main communication device between plants and animals. These are relatively small molecules (up to $400 \mathrm{u}$ ) with the power and functions comparable to human words, and are applied in survival and speciation strategies, attracting pollinators, recruiting help and repelling predators. "Welcome messages" to pollinators are expressed in coded "sentences" composed of several molecules which lure these animals to 
the flowers by advertising some reward (food and or any other material important for survival or reproduction). Therefore the floral visitors transport pollen from one flower to the other (often promoting cross pollination) unaware of their important role in plant survival or in plant-animal relationships. These chemical substances involved in interspecific chemical communication are generally named allomones.

Any successful plant species has its own chemical strategy to convey messages to the biotic environment. If the plants depend on animal vectors to achieve pollination, they have to link the pollinators survival to their own. Thus, by observing nature one can, in principle, detect the different mutualistic mechanisms, but to understand these, one has to reach the molecular level and decipher the encoded sentences built into the volatile composition and rewards. Orchids use efficient attraction strategies allowing the survival of species by either offering rewards (diacylglycerol in Oncidiinae ${ }^{1}$ ) or not rarely, deceiving the pollinators when the flowers are rewardless. ${ }^{1,2}$ Many orchids are "food-frauds", that is, they show flower features (flower shape, fragrances, etc.) that provoke the attraction of food-seeking pollinators ${ }^{2,4}$. A more elaborate floral strategy is to mimick the fragrance and appearance of female insects. ${ }^{3,5,6,7}$ Such fragrances are responsible for long-distance insect attraction. Attracted male insects attempt copulation with the insect-like labellum and, during this behaviour, promote the pollination process. ${ }^{2,6,7,8}$

Attempting to decipher orchid floral chemistry and their encoded messages to a specific group of pollinators, we have chosen species growing in the same environment (Atlantic rain forest in the southeastern part of Brazil) that trigger different responses of the ecosystem inhabitants and offer distinct rewards: fragrant oil (Stanhopea lietzeii (Regel) Schltr., S. insignis Frost ex Hooker), pseudopollen (Polystachya estrellensis Rchb. f.), nectar and pollen (Psilochilus modestus Barb. Rodr) and nectar (Epidendrum secundum Jacq. and E. paniculatum Ruiz \& Pav. $)^{1}$

\section{Results and Discussion}

To study the floral attracting substances we have selected GC/MS as the main analytical tool, by injecting small floral parts using a solid injection device. ${ }^{10}$ For the present group of orchids, this methodology was not appropriate due to the detection of large amounts of fatty acids, belonging to the epicuticular components. As alternative methodologies we have probed static headspace and SPME ${ }^{11}$ using several fiber coatings (75 um Carboxen-PDMS, 30 um polydimethylsiloxane and 85 um polyacrylate), reaching the conclusion that these methods are not as effective as dynamic trapping with Porapak-Q ${ }^{\circledR} .^{12,13}$ This technique furnished reproducible results and was selected for the present investigation.

Stanhopea lietzeii and S. insignis are fragrant oil rewarding orchids which are pollinated by Euglossini, neotropical bees, know for pollinating about 650 orchid species. ${ }^{14}$ These bees collect fragrant oils, possibly with the purpose of attracting conspecific males in an aggregation where 
mating occur. This plant-insect relationship is often highly specific, and is an important mechanism to maintain the species integrity. ${ }^{15}$

In the fragrant oils-producing orchids (Table 1), the floral fragrance and the floral oil possess the same constituents. Therefore the orchid is ingeniously saving energy by combining the floral attraction and the floral reward in the same product.

The S. lietzeii floral volatile composition is relatively simple (Table 1) depicting 9 components arising from the shikimic biosynthetic pathway with benzyl benzoate as the major constituent. Minor constituents, linalool and camphor, are derived from the isoprenoid biosynthetic pathway. Indol was the second major constituent and the only nitrogen containing compound. Benzyl benzoate is present in several species of Stanhopea and other Orchidaceae floral volatiles. ${ }^{15,16}$ Field observations revealed that Euglossa cordata, Euglosa annectans e Eufriesea aff. pulchra were floral visitors of S. lietzeii but only Eufriesea aff. pulchra was able to achieve pollination.

Chemistry is certainly responsible for the attraction of these Euglossini bees (males), triggering searching behavior and causing aggregation. It is not evident whether attraction arises from one pure compound or from the mixture. Ackerman observed that Euglossini Eufriesea aff. pulchra were attracted by methyl benzoate and linalool ${ }^{14}$. The behavioural influence of this component might not be unique and other components or the floral "bouquet" might be just as active. Indeed Ackerman used benzyl benzoate in Panamá to attract Eufrisea ornata, Euglossa hemichlora, Euglossa cyanaspis e Exaerete smaragdina ${ }^{14}$. However floral volatile bouquets differ within populations and according to the age of flowers and male bees learn where to search. Therefore, it is difficult to conclude what compound or mixture is indeed attracting the pollinator. Furthermore the Euglossini males do change their odoriferous compound preference from season to season and from place to place. $^{17}$

Four components (benzyl alcohol, benzyl acetate, $\alpha$-cubebene and benzaldehyde), were detected in Stanhopea insignis floral volatiles (Table 1). Of these the benzyl alcohol is present in 97\% relative abundance. Williams \& Whitten (1983) have also detected benzyl alcohol as a major component of the Stanhopea impressa Rolfe and Catasetum expansu Reich. F. floral fragrances and both species are pollinated by males of Euglossini bees

Field observations revealed that $S$. insignis was visited by Eufriesea purpurata and Eulema cingulata but Eufriesea purpurata was the pollinator, as revealed by pollinia removal. Male Eulema cingulata respond to benzyl acetate baits. ${ }^{14,17,18}$

Finally, both Stanhopea lietzeii and Stanhopea insignis attract few visitors and are highly specific, possessing only one euglossine species as effective pollinator. It is worth pointing out that both species have major components (benzyl alcohol and benzyl benzoate) of analogous biosynthetic pathways.

Changing our focus, we chose the food rewarding orchids Polystachya estrellensis (pseudopollen), Psilochillus modestus (pollen and nectar), Epidendrum secundum (nectar) and E. paniculatum (nectar). 
The species Polystachya estrellensis belong to a genus with about 200 species and the floral fragrance of Poslystachya campyloglossa Rolfe, P. cultriformis (Thouars) Lindl. ex Spreng., P. fallax Kraenzl. and P. mazumbaiensis Cribb \& Podzorski were previously studied. ${ }^{13}$ Species of Polystachya possess a dusty deposition on the labelum surface. This dust is known as pseudopollen which is produced by detached cells of trichomes. These cells are rich in nutritious substances that are collected by bees. ${ }^{19}$

The trapped floral volatiles are mostly (95\%) composed of monoterpenes ( $\beta$-myrcene, trans$\beta$-ocimene, linalool and geranial) and sesquiterpenes ( $\alpha$-copaene and $\delta$-cadinene). The monoterpenes are responsible for $85 \%$ of the total amount of the fragrance mixture (Table 1 ). This and the pseudopollen, ascertain pollinator visits, among which Trigona spinipes was most effective in carrying pollinia from and to the visited flowers.

Most pollen-rewarding flowers possess a fragrance composed of geranial, linalool and trans$\beta$-ocimene ${ }^{20,21}$ and are visited and frequently pollinated by pollen collecting insects. Among these, Apis mellifera (Apidae) is worth mentioning for its economical importance and also due to the similarity between the fragrances of the visited flower and the Apis own odor, secreted by pheromonal glands (geranial, neral Z, (E,E)-farnesol, nerol, E-nerolic acid and E-geranic acid). ${ }^{22,23}$ Thus the $P$. estrellensis strategy of offering pseudopollen and possessing a fragrance similar to pollen-rewarding flowers is another example of mimicking a successful pollination mechanism and attracting pollen-collecting bees.

The presence of linalool in Polystachya estrellensis fragrances (Table 1) might have attracted eventual euglossini visitors but this never occurred, notwithstanding the abundance of euglossini in the environment.

Psilochilus, the third orchid genus we selected to study, possesses seven terrestrian native species growing in the Atlantic rain forest of southeastern part of Brazil. ${ }^{24}$ They offer pollen and nectar as rewards and are visited by pollen-collecting bees belonging to the genus Plebeia (Plebeia droryana) and Trigona (Trigona spinipes). The Psilochilus modestus flower fragrance is mainly composed of aromatic compounds like benzyl alcohol and benzyl tiglate (46\%) (Table1). The remaining constituents are isoprenoids like 6-methyl-5-hepten-2-one (an irregular isoprenoid), geranyl acetone (oxygenated terpene), $\gamma$-cadinene, $\alpha$-ylangene (sesquiterpenes) and nerolidol (oxygenated sesquiterpene).

Some of the fragrance constituents, like 6-methyl-5-hepten-2-one, geranyl acetone and benzyl alcohol, detected in Psylochyllus modestus, are also present in other floral volatiles of pollen rewarding flowers, eg Papaver rhoeas L. ${ }^{24}$ and Rosa rugosa Thunb. The major constituent of the Rosa rugosa pollen fragrance is geranyl acetone. ${ }^{20}$ To conclude that any of these constituents are signaling pollen presence and are attracting pollen-collecting bees requires further experiments.

Moths, butterflies and birds, mainly pollinate Epidendrum, a genus of about 1000 species, therefore distinct from the previous examples.

The floral fragrances of Epidendrum ciliare L., E. nocturnum Jacq., E. lacertinum Lindland. E. aromaticum ${ }^{13}$ were studied but, in general, the floral fragrance is weak to human perception. 
DeVries \& Stiles $^{25}$ suggested the presence of pyrrolizidinic alkaloids in E. paniculatum flowers. These results were not observed in previous analyses of several other Epidendrum species, including E. floribundum (E. paniculatum synonym) ${ }^{26}$

We have investigated two species, Epidendrum paniculatum and Epidendrum secundum. The floral extracts did not reveal the presence of alkaloids by using thin layer chromatography and specific dyeing reagents (Dragendorff, Meyer and Wagner), following the protocol indicated by Ugaz. $^{27}$ The floral fragrance of Epidendrum paniculatum was trapped and analyzed revealing the presence of monoterpenes containing oxygen and sesquiterpenes having no oxygen. The same was true for the floral volatile constituents of Epidendrum secundum, which is mainly constituted by sesquiterpenes non-oxygenated. Trapping the floral fragrance of E. secundum was not an easy task and several attempts were necessary before any results were achieved. The trapping time had to last $21 \mathrm{hr}$ to allow constituent detection (Table 1). Daily floral visitor were daily lepidoptera and Bombus bees. Of these the diurnal lepidoptera, Hesperiidae, were the main pollinators, interested in collecting nectar from E. secundum.

The floral scents of these two species share the constituents but they are very different in floral signaling abundances, E. secundum emits a very weak odor but is colorful (pink) therefore attracting butterflies that are color as well as scent oriented insects ${ }^{28}$. To overcome its colorless features (white) E. paniculatum emits a strong scent to be able to attract pollinators (butterflies).

To make definite conclusions about the floral scent role in signaling butterflies and bees is a complex matter and to assign a specific compound or a specific class of compounds to a specific group of pollinators seems a difficult task. From our results we could conclude that terpenes in general and linalool might be responsible for attracting butterflies to E. secundum and E. paniculatum. Our results are supported by previous investigation ${ }^{29}$ on floral fragrances of 22 butterfly pollinated species (13 plant families, with orchids among them) suggesting that linalool and its derivatives are responsible for the attraction of American butterflies, a preference that is switched to benzenoids with Europe butterflies. Therefore the "pollination syndromes" or the suites of floral scent adaptation to different groups of pollinators is not a well defined matter and, in most cases, the "bouquet" is responsible for the attraction and not just one compound or compound class is responsible for the pollination attraction. These as well as floral shapes and colors are responsible for linking plants to a specific group of pollinators.

\section{Experimental Section}

Stanhopea lietzeii; Stanhopea insignis, Polystachya estrellensis, Psilochilus modestus e Epidendrum secundum were collected in the southeastern part of Brazil. Voucher specimens are deposited in the herbarium at the Botany Department of the Universidade Estadual de Campinas, as Stanhopea lietzeii (voucher \# E: R. Pansarim 88); Stanhopea insignis (voucher \# E. R. Pansarim 710), Polystachya estrellensis (voucher \# E. R. Pasanrim 245); Psilochilus modestus 
(voucher \# E. R. Pansarim 132) e Epidendrum secundum (voucher \# E. R. Pansarim, 190). Epidendrum paniculatum. (voucher \# E. R. Pansarim)

GC/MS. Analyses were carried out using a HP-5890/5970 system equipped with a J and W Scientific DB-5 fused silica capillary column $(30 \mathrm{~m}$ x $0.25 \mathrm{~mm}$ x $0.25 \mu \mathrm{m})$. Column temperatures were programmed from 50 to $290{ }^{\circ} \mathrm{C}$ at $4{ }^{\circ} \mathrm{C} \mathrm{min}{ }^{-1}$. Injector temperature was $220{ }^{\circ} \mathrm{C}$. Helium was used as carrier at a gas of flow rate $1 \mathrm{~mL} \mathrm{~min}^{-1}$. The MS were taken at $70 \mathrm{eV}$. Scanning speed was 0.84 scans s$^{-1}$ from $\mathrm{m} / \mathrm{z} 40$ to 550 . The volatiles were analyzed by GC/MS and identification was made on the basis of standard compound coinjection and comparison of retention indices ${ }^{30}$ as well as by computerized matching of the acquired mass spectra with those stored in the Wiley mass spectral library of the GC/MS data system and other published mass spectra. ${ }^{31}$

Dynamic headspace. Glass vials compatible to the flower size or inflorescence constructed with na open end to enable flower insertion with the opposite end linked to a glass tube $(5 \mathrm{~cm}$ long and $0.5 \mathrm{~cm}$ of internal diameter) containing 30-60 mg of Porapack-Q ${ }^{\circledR}$ held by and glass wool at both ends (both the Porapack and the glass wool were previously treated with dichloromethane and heated to $150{ }^{\circ} \mathrm{C}$ under vacuum). The fragrance was air-carried through the absorbing polymer at a $500 \mathrm{~mL}$ min flow rate using an aspirator pump for 2 to 4 hours for Stanhopea lietzeii; S. insignis, Polystachya estrellensis, Psilochilus modestus and Epidendrum paniculatum and $21 \mathrm{~h}$ for E. secundum. The polymer was removed from the glass vial and the trapped components were eluted with $1.5 \mathrm{~mL}$ of dichloromethane. The solvent was evaporated under a nitrogen flow to $20 \mu \mathrm{L}$. Simultaneous GC/MS analyses of the floral volatiles and of the blank samples (trapping volatiles in the environment) allowed the detection of the components in the floral fragrances. ${ }^{12}$

Solid injection. With the help of tweezers and scalpel the sepal, petal and labellum from fresh flowers were cut and introduced, one at a time, into the solid injector and analyzed by GC/MS. The a solid injector device was manufactured in our laboratory. ${ }^{10}$

Static headspace-solid phase microextraction. Method 1. Into a glass vial possessing two openings, similar to that used in the dynamic headspace experiment was introduced a flower at one end. The other opening was closed with a rubber septum through which the SPME fiber was introduced (75 um Carboxen-PDMS, 30 um polydimethylsiloxane or 85 um polyacrylate - all from Supelco $\left.{ }^{\circledR}\right)$. The system was closed for 1 hour. The trapped volatiles were analysed by GC/MS. Method 2. $4 \mathrm{~g}$ of freshly collected flowers were deposited in a glass vial of $25 \mathrm{~mL}$ containing water $(7 \mathrm{ml})$. The system was closed and maintained under stirring at $50{ }^{\circ} \mathrm{C}$ for 30 minutes. The SPME fiber was introduced (75 um Carboxen-PDMS, 30 um polydimethylsiloxane or 85 um polyacrylate) and exposed during $1 \mathrm{hr}$. and the trapped volatiles were analysed by GC/MS. ${ }^{11}$ 


\section{Acknowledgements}

The authors are indebted to FAPESP (Fundação de Amparo a Pesquisa do Estado de São Paulo proc. $n^{\circ}$. 98/05097-0) and CNPq (Conselho Nacional de Pesquisa e Tecnologia) for scholarships and other support. The authors are also thankful to the botanical orchid nursery of the Universidade Estadual de Campinas.

Table 1. Chemical composition of Stanhopea lietzeii , S. insignis, Polystachya estrellensis, Psilochilus modestus, Epidendrum secundum and E. paniculatum floral fragrances

\begin{tabular}{|c|c|c|c|c|c|c|c|c|c|}
\hline \multirow[t]{2}{*}{ Compound } & \multirow[t]{2}{*}{$\mathbf{R I}^{\mathrm{C}}$} & \multirow[t]{2}{*}{$\mathbf{R I}^{\mathbf{L}}$} & \multirow[t]{2}{*}{ IM } & \multicolumn{6}{|c|}{ Relative abundances } \\
\hline & & & & $\begin{array}{c}S . \\
\text { lietzeii }\end{array}$ & $\begin{array}{c}\text { S. } \\
\text { insignis }\end{array}$ & $\begin{array}{c}P . \\
\text { estrellensis }\end{array}$ & $\begin{array}{c}P . \\
\text { modestus }\end{array}$ & $\begin{array}{c}E . \\
\text { secundum }\end{array}$ & $\begin{array}{c}\text { E. } \\
\text { paniculatum }\end{array}$ \\
\hline \multicolumn{10}{|l|}{ Irregular terpene } \\
\hline \multicolumn{10}{|l|}{ 2-one } \\
\hline Monoterpene & & & & & & & & & - \\
\hline$\beta$-mircene & 0988 & 0991 & $\mathrm{~b}$ & - & - & 18.3 & - & - & - \\
\hline trans- $\beta$-ocimene & 1052 & 1050 & $\mathrm{~b}$ & - & - & 6.8 & - & - & 25.2 \\
\hline $\begin{array}{c}\text { trans - linalool } \\
\text { oxide }\end{array}$ & 1083 & 1088 & $\mathrm{~b}$ & $\operatorname{tr}$ & - & - & - & - & - \\
\hline linalool & 1097 & 1098 & $\mathrm{a}$ & 4.0 & - & 49.3 & - & - & 33.8 \\
\hline camphor & 1140 & 1143 & $\mathrm{a}$ & $\operatorname{tr}$ & - & - & - & - & - \\
\hline geranial & 1268 & 1270 & $\mathrm{~b}$ & & - & 11.1 & - & - & - \\
\hline geranyl acetone & 1449 & 1453 & $\mathrm{~b}$ & 0.4 & - & - & $\operatorname{tr}$ & - & - \\
\hline \multicolumn{10}{|l|}{ Sesqueterpenes } \\
\hline$\alpha$-cubebene & 1346 & 1351 & $\mathrm{~b}$ & - & $\operatorname{tr}$ & - & - & 4.0 & - \\
\hline$\alpha$-copaene & 1368 & 1372 & $\mathrm{~b}$ & - & - & 9.8 & - & 16.3 & 0.5 \\
\hline$\alpha$-ylangene & 1373 & 1372 & $\mathrm{~b}$ & - & - & - & 3.0 & - & - \\
\hline$\beta$-longipinene & 1405 & 1398 & $\mathrm{~b}$ & - & - & - & - & 9.8 & - \\
\hline $\begin{array}{c}\text { trans- } \\
\text { caryophyllene }\end{array}$ & 1420 & 1418 & $\mathrm{~b}$ & - & - & - & - & - & 0.7 \\
\hline$\alpha$-patchoulene & 1450 & 1456 & $\mathrm{~b}$ & - & - & - & - & $\operatorname{tr}$ & - \\
\hline $\begin{array}{c}\text { allo- } \\
\text { aromadendrene }\end{array}$ & 1462 & 1461 & $\mathrm{~b}$ & - & - & - & - & 6.5 & - \\
\hline germacrene-D & 1480 & 1483 & $\mathrm{~b}$ & - & - & - & - & - & 7.5 \\
\hline bicyclogermacrene & 1498 & 1494 & $\mathrm{~b}$ & - & - & - & - & - & 0.4 \\
\hline$\alpha$-muurolene & 1500 & 1499 & $\mathrm{~b}$ & - & - & - & - & - & 0.2 \\
\hline$\gamma$-cadinene & 1515 & 1513 & $\mathrm{~b}$ & - & - & - & 5.4 & 5.8 & - \\
\hline
\end{tabular}


Table 1. (continued)

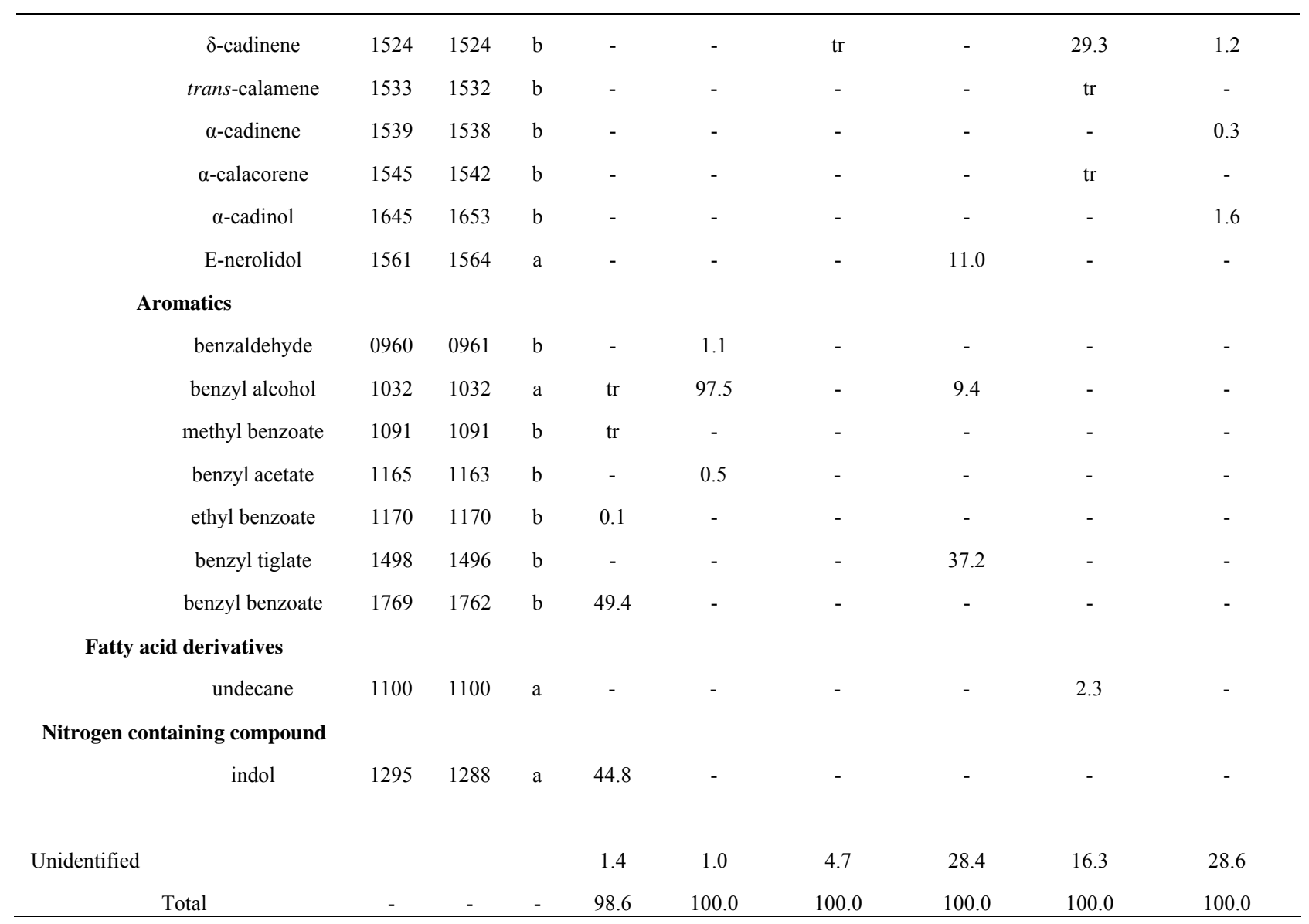

$\mathbf{R I}^{\mathrm{C}}$-Calculated Retention Index, ${ }^{\text {Error! Bookmark not defined. }} \mathbf{R I}^{\mathrm{L}}$-Literature ${ }_{\text {Retention Index, }}$,rror! Bookmark not defined. IM: a- identification by Standard coinjection b - Identification by mass spectrum matching with those in the Wiley library and retention index tr- trace

\section{References}

1. Reis, M. G.; de Faria A. D.; do Amaral M. D. E.; Marsaioli A. J. Tetrahedron Lett. 2003, 44, 8519.

2. Pijl, L. V.; Dodson, H. Orchid flowers their pollination and evolution; University of Miami Press: Florida, 1969.

3. Ayasse, M.; Schiestl, F.P.; Paulus, H.F.; Lofstedt, C.; Hansson, B; Ibarra, F. Francke, W.; Evolution 2000, 54, 1995

4. Ackerman, J. D. Lindleyana 1986, 1, 108.

5. Borg-Karlson AK.; Tengo J. J. Chem. Ecol. 1986, 12, 1927.

6. Van der Cingel N. A. An Atlas of orchid pollination. America, Africa, Asia and Australia; Balkema Publisher: Rotherdam, 2001. 
7. Van der Cingel N.A. An Atlas of orchid pollination: European Orchids; Balkema Publisher: Rotherdam, 1995.

8. Singer, R. B.; Flach, A.; Koehler, S.; Marsaioli, A. J.; Amaral, M. do C. E. Ann. Bot. 2004, 93, 755.

9. Pansarin, E. R.; Amaral, M. C. E. in prep.

10. Silva, U. F.; Borba, E. L.; Semir, J.; Marsaioli, A. J. Phytochemistry 1990, 50, 31.

11. Palwliszyn, J., Solid phase microextraction theory and practice; Wiley-VCH: New York, 1997.

12. Raguso, R. A.; Pellmyr, O. Oikos 1998, 81, 238

13. Kaiser, R., The scents of orchids, olfactory and chemical invstigations; Elsevier: Amsterdan, 1993.

14. Ackerman, J. D. Biotropica 1989, 21, 340.

15. Williams, N. H.; Written, W. M. Biol. Bull. 1983, 164, 355.

16. Knudsen, J. T.; Tollsten, L.; Bergström, L. G. Phytochemistry 1993, 33, 253.

17. Peruquetti, R. C.; Campos, L. A. O.; Coelho, C. D. P.; Abrantes, C. V. M.; Lisboa, L. C. O. Rev. Bras. Zool. 1999, 16, 101.

18. Williams, N. H.; Dodson, C. H. Evolution 1972, 26, 84.

19. Davies, K. L.; Roberts, D. L.; Turner, M. P. Ann. of Botany 2002, 90, 477.

20. Dobson, H. E. M.; Bergström, J.; Bergström, G.; Groth, I. Phytochemistry 1987, 26, 3171.

21. Dobson. H. E. M.; Arroyo, J.; Bergström, G. Plant Systematic and Evolution 2000, 222, 63.

22. Hick, S.; Luszniak, M. C.; Pickett, J. A. Nat. Prod. Rep. 1999, 16, 39.

23. Harbone, J. B. Nat. Prod. Rep. 1989, 85.

24. Mabberley, D. J. The Plant Book, $2^{\text {nd }}$ Edn. Cambridge, 1997.

25. DeVries, P. J.; Stiles, F. G. Biotropica 1990, 22, 290.

26. Lüning, B. Acta Chem. Scand. 1964, 18, 1507.

27. Ugaz. O. L. Investigation fitoquímica: métodos en el studio de productos naturales; Pontificia Universidad Catolica del Peru: Fondo Editorial, Peru, 1988.

28. Dobson, H.,E.,M., Floral Volatile in insect biology. IN. Bernays, E. A. Insect-plant interaction, Vol. V. CRC Press: Boca Raton, 1994.

29. Andersson, S.; Nilsson, L. A.; Groth I.; Bergstrom, G. Bot. J. Linn. Soc. 2002, 140, 129.

30. Van den Dool, H., Kratz, P. D. J. J. Chrom. 1963, 11, 463.

31. Adams, R. P. Identification of essencial oil components by gas chromatography/mass spectrometry; Allured publishing Co.: Illinois, 1995 